\title{
Diz çevresi osteotomisi sonrası total diz protezi uygulaması
}

\section{Total knee arthroplasty after around the knee osteotomy}

\author{
Olcay Güler ${ }^{1}$, İrfan Esenkaya ${ }^{2}$, Feridun Yumrukçal ${ }^{1}$ \\ ${ }^{1}$ Memorial Sağlık Grubu, Şişli Hastanesi, Ortopedi ve Travmatoloji Kliniği, Şişli, İstanbul \\ ${ }^{2}$ Emekli Öğretim Üyesi, SANTE Tıp Merkezi Ortopedi ve Travmatoloji Bölümü, Kalamış, İstanbul
}

Diz çevresi osteotomileri, tek kompartman artrozu ile birlikte varus veya valgus deformitesi olan hastalarda uygulanan cerrahi tedavi yöntemlerindendir. Osteotomiler, proksimal tibiadan, distal femurdan veya her iki bölgeden yapılabilir. Diz çevresi osteotomileri sonrası total diz protezi (TDP) uygulanacak olgularda ameliyat öncesi planlamanın iyi yapılması önem arz etmektedir. Daha önce yapılan insizyon nedbelerinin (skarlarının) yerleşimleri dikkate alınarak uygun insizyon seçimi yapılması gereklidir. Özelikle proksimal tibia kapalı kama osteotomileri sonrası görülen patellar tendonda fibrozise ve patella bajaya bağlı olarak ameliyat esnasında patellanın laterale devrilmesi veya dışa doğru döndürülmesinde (everte edilmesinde) yaşanabilecek sorunlara karşı hazırlıklı olunmalıdır. Ayrıca osteotomi hattındaki tespit materyalleri, protez komponentlerinin uygulanmasını engelleyecekse çıkarılmalıdır. Ameliyat sırasında osteotomi sonrası görülen anatomik değişiklikleri göz önüne alarak kemik kesiler yapılmalıdır. Özellikle ileri derece koronal veya sagittal düzlem deformiteleri olan hastalarda instabilite açısından dikkatli olunmalıdır ve kısıtlayıcı protez seçenekleri hazır bulundurulmalıdır. Yeterli hazırlık ve planlama sonrasında doğru cerrahi teknikle uygulanacak olan TDP, klinik ve radyolojik sonuçlar bakımından tatminkârdır.

Anahtar sözcükler: gonartroz; deformite; proksimal tibial osteotomi; distal femoral osteotomi; total diz protezi

\begin{abstract}
Osteotomies around the knee are surgical treatment techniques which are applied to patient who have varus or valgus deformity with single compartment osteoarthropathy. Osteotomies may be applied for proximal tibia, distal femur or both sites. It is very important to make a detailed pre-operative planning for patient who will receive total knee arthroplasty after an osteotomy around knee joint. Incision choice must be done while taking previous incisions to account. Surgeon must be precautious about especially proximal tibia closed wedge osteotomy caused patellar tendon fibrosis and patella baja related issues which may develop while overturning or shifting patella to lateral side. In addition to this implants must be removed from osteotomy site if they would prevent to apply arthroplasty materials. Bone cuttings must be done with the consideration of osteotomy related anatomical changes while surgery. Surgeon must be precautious about the instability especially for the patient who have serious coronal and sagittal plane deformities and because of this stabilizing prosthesis options must be ready while surgery. Total knee arthroplasty that would be performed with correct surgical technique after sufficient preoperative planning is satisfactory in terms of clinical and radiological results.
\end{abstract}

Key words: gonartrosis; deformity; proximal tibial osteotomy; distal femoral osteotomy; total knee arthroplasty

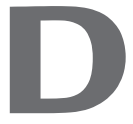

iz çevresi osteotomileri, tek kompartman artrozu ile birlikte varus veya valgus deformitesi olan hastalarda yaygın uygulanan cerrahi tedavi seçeneklerindendir. Osteotomilerdeki amaçlar, mekanik eksenin düzeltilmesi ile diz eklemine gelen yükü tibia platosuna dengeli olarak dağıtmak ve hastanın şikâyetlerini azaltmaktır. Bu osteotomiler, proksimal tibiadan, distal femurdan veya her iki bölgeden yapılabilir. Genellikle varus deformitesinin eşlik ettiği medial kompartman artrozu olan olgulara proksimal tibia valgus osteotomisi (PTVO), valgus deformitesinin eşlik ettiği lateral kompartman artrozu olan olgulara da distal femoral varus osteotomisi (DFVrO) uygulanmaktadır. Osteotomiler sonrasında erken dönemde başarılı klinik sonuçlar bildirilse de uzun dönemde hastalara total diz protezi (TDP) uygulamak gerekebilir. ${ }^{[1]}$ PTVO sonrası takiplerde 10 yıllık sağkalım \%79-97,6 ve 15 yıllık sağkalım ise \%56-65,5 olarak bulunmuştur. ${ }^{[2,3]}$ Diz çevresi osteotomisi sonrası uygulanan TDP'de hedef; hareketli, stabil (dengeli), ağrısız ve fonksiyonel bir diz elde edilmesidir. Makalemizde, diz çevresi (proksimal tibia ve/veya distal femur) osteotomileri sonrası TDP uygulamasının özelliklerini ve zorluklarını güncel literatür eşliğinde gözden geçirmek amaçlanmıştır.

iletişim / Contact: Doç. Dr. Olcay Güler • E-posta / E-mail: olcayguler77@gmail.com

ORCID iD: Olcay Güler, 0000-0002-0022-0439 • İrfan Esenkaya, 0000-0002-7321-0012 • Feridun Yumrukçal, 0000-0002-5714-7324 


\section{PROKSIMAL TIBIAAL OSTEOTOMI SONRASI TOTAL DIZ PROTEZI}

Medial kompartman artrozunun eşlik ettiği varus deformitesi olan hastalarda proksimal tibia valgus osteotomisi (PTVO) uygulanmaktadır. Birçok farklı PTVO tekniği tanımlanmış olsa da en sık olarak; tek planda (uniplanar) veya iki planda (biplanar) medial açık kama osteotomisi (MAKO), lateral kapalı kama osteotomisi (LKKO) veya dome osteotomisi yöntemleri uygulanmaktadır. Özellikle MAKO tekniği; kolay düzeltme elde edilebilmesi, kemik stoğunu koruması, proksimal tibiofibular eklemi bozmaması ve peroneal sinir hasar riskinin az olması dolayısıyla son yıllarda daha yaygın uygulanmaktadır. PTVO sonrasında TDP endikasyonları ile primer TDP endikasyonları benzerlik içermektedir. PTVO'dan TDP'ye geçiş nedenleri arasında; diz artrozunun ilerlemesi, yetersiz düzeltme (korreksiyon), düzeltme derecelerinde kayıp, hareket kısıtlılığ ve konservatif tedaviye cevap vermeyen diz ağrısı sayılabilir. ${ }^{[2]}$

\section{PTVO'dan TDP'ye Geçişteki Zorluklar ve Ameliyat Öncesi Değerlendirme}

PTVO'dan TDP'ye geçiş birçok zorluklar içermektedir. Bu zorlukların başında patellofemoral eklemi ilgilendiren; patella baja ve patellar tendonda yapışıklıklar, tibio-femoral eklem koronal düzlemdeki varus-valgus deformiteleri ve proksimal tibia anatomik ekseninin mediale yer değiştirmesi, sagittal düzlemde posterior tibial eğim açısındaki değişim ve bağ dengesizliği sayılabilir. Bu zorluklar nedeniyle protezin doğru pozisyonda uygulanması, patellofemoral uyumun elde edilmesi ve bağ dengesi sağlanması TDP cerrahisinde başarı getiren faktörlerdir. ${ }^{[4]}$

Osteotomi sonrası TDP yapılacak hastalara, ameliyat öncesi yeterli klinik ve radyolojik planlama yapılması, tedavi başarısını doğrudan etkilemektedir. Özellikle karşılaşılacak zorluklar belirlenmeli ve gerekli önlemler alınmalıdır. Fizik muayenede daha önceden yapılmış kesilere ait nedbeleri (insizyon skarları) cilt doku beslenmesinde sorun oluşturarak TDP sonrası yara yeri problemlerine neden olabilmektedir. PTVO sonrası TDP'ye geçişte; yumuşak doku problemleri, patellanın dışa doğru döndürülme (everte edilme) zorluğu, proksimal tibia sagittal-koronal plan deformiteleri ile patella infera gibi patellofemoral eklem sorunlarının var olabileceği bilinmelidir. Osteotomi tespiti için kullanılan malzemelerin özelliğinin önceden belirlenmesi ve implant çıkarılması için gerekli malzemelerin hazırlanması ameliyat sırasında kolaylık sağlayabilmektedir. ${ }^{[2,3]}$

Hastaların ameliyat öncesi antero-posterior (önarka) ve lateral (yan) diz grafileri (Şekil 1), patella tanjansiyel grafileri ve her iki alt ekstremite ortoröntgenografileri incelenmelidir. Ayrıca MAKO sonrası posterior tibial eğim (PTE) açısında artma (Şekil 2) ve LKKO ile dome osteotomisi sonrası PTE açısında azalma olabileceği için ameliyat öncesi ölçümler yapılmalıdır. Ayrıca lateral diz grafileri de, patellanın konumunun değerlendirilmesi açısından önemlidir (Şekil 3). Cerrahi öncesi çekilecek antero-posterior grafilerle, tibia anatomik ekseni ile tibia plato ekseni arasındaki değişim
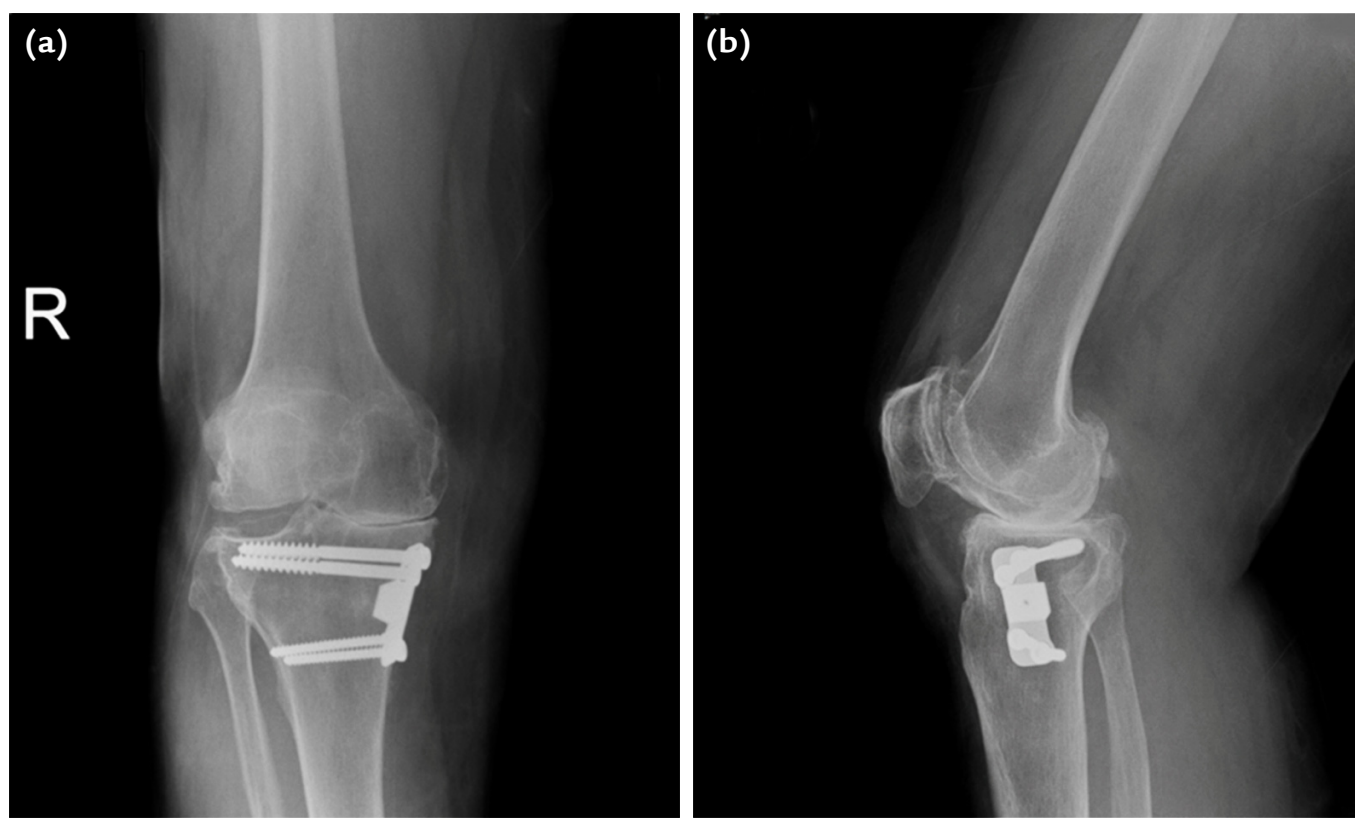

Şekil 1. a, b. On beş yıl önce sağ diz proksimal tibial medial açık kama valgus osteotomisi yapılan hastanın ön-arka (a) ve yan grafileri (b). 


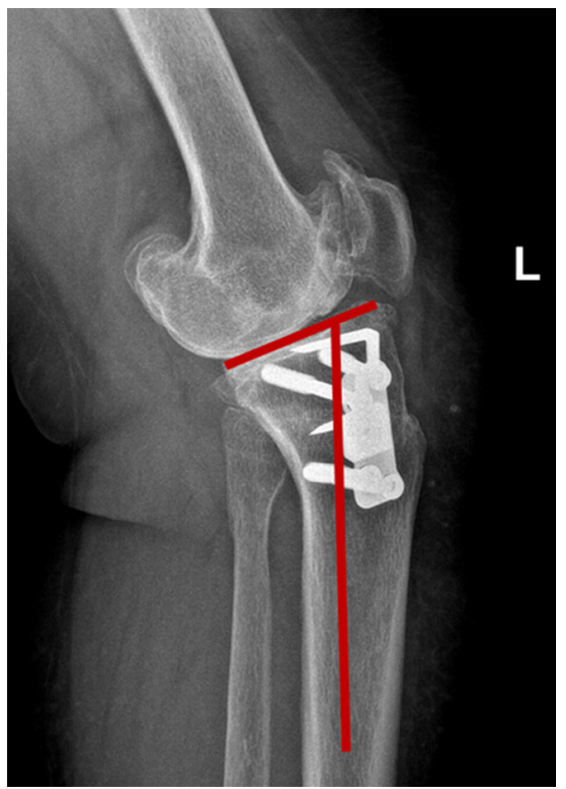

Şekil 2. Sol diz proksimal tibia medial açık kama valgus osteotomisi yapılan hastanın ameliyattan 13 yıl sonra çekilen yan (lateral) grafisinde artmış posterior tibial eğim açısının gösterilmesi (kırmızı çizgiler).

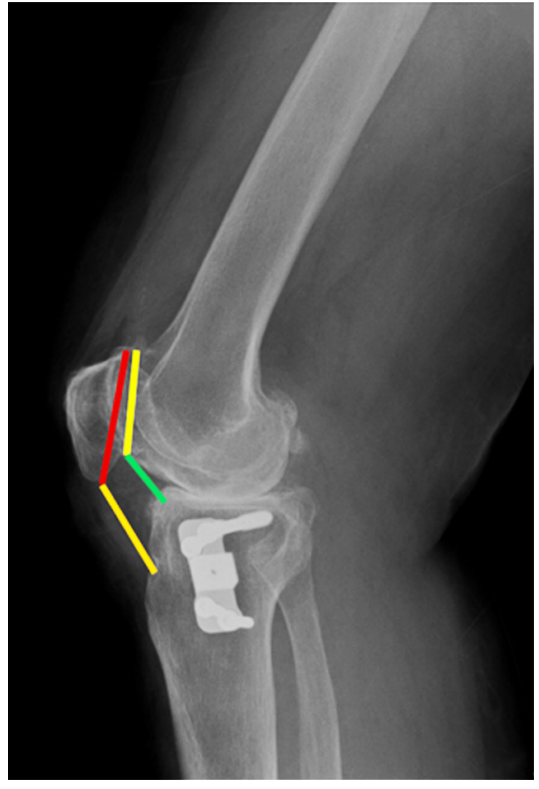

Şekil 3. Sağ diz yan (lateral) grafide patella baja görüntüsü: Öndeki; Insall-Salvati indeksi, patellar tendon uzunluğu (sarı çizgi)/ patellanın diyagonal uzunluğu (kırmızı çizgi). Arkadaki; Caton-Deschamps indeksi, patella eklem yüzey alt kenarı ile tibianın ön-üst köşesi arası mesafe (yeşil çizgi)/ patella eklem yüzey uzunluğu (sarı çizgi). incelenmelidir. TDP'ye geçiş sırasında yetersiz düzeltme, varus tekrarı, aşırı düzeltme veya valgus deformitesi ile karşılaşılabilir. ${ }^{[2,3]}$

\section{İnsizyon Seçimi}

Tibia proksimal medial-lateral uzunlamasına (longitudinal) veya enlemesine (transvers) kesi nedbeleri (insizyon skarları) ameliyat öncesi değerlendirilmelidir. Transvers insizyonlar TDP cerrahisi için yapılacak longitudinal yeni insizyon için genellikle sorun oluşturmamaktadır. Diz bölgesinin cilt kan dolaşımı, beslenmesi ve lenf drenajı medialden olduğu için lateral cilt dokusu savunmasızdır. Dolayısıyla lateral cilt dokusu TDP sonrası sorun olarak karşımıza çıkabilmektedir. Eski insizyon kullanılarak TDP yapılabilir. Daha önceki birden fazla insizyon skarlarından en lateralde olanı TDP cerrahisinde kullanılmalıdır. Ancak implant çıkarma için farklı bir insizyon yapılacaksa iki insizyon arasındaki mesafe en az $6 \mathrm{~cm}$ olmalıdır. ${ }^{[2-4]}$

\section{Patellofemoral Sorunlar}

Proksimal tibia valgus osteotomisi sonrası patellofemoral eklem biyomekaniğinde ve anatomisinde değişikliklere neden olabilmektedir. LKKO, tibial tüberkülün proksimalinden yapıldığından dolayı patella alta beklenirken, metafiz kemik kalınlığının azalmasına bağlı pateller tendonda gevşeklik, yapışıklık veya ameliyat sonrası immobilizasyona bağlı yaygın olarak patella baja görülmektedir. MAKO sonrası da patellar tendonun göreceli kısalmasına bağlı patella baja görülür. ${ }^{[2]}$ MAKO hattındaki açılma miktarının yaklaşık yarısı kadar patella inferiora yer değiştirmektedir. ${ }^{[5]}$

Proksimal tibia valgus osteotomisi sonrası patellar tendonda fibrozise, osteotomi çevresindeki yumuşak doku yapışıklıklarına veya patella bajaya bağlı patellanın dışa doğru döndürülmesi (everte edilmesi) zor olabilmektedir. ${ }^{[6]}$ Bu nedenle patellar tendonu koruyarak infrapatellar ve periosteal yapışıklıklar içeren iyi bir gevşetme yapılmalıdır. Buna rağmen patella dışa döndürülemiyorsa, lateral retinakular ve patellofemoral ligament gevşetmesi, rektus snip yaklaşım, kuadriseps "V-Y" plasti ve tibial tüberkül osteotomisi gibi yaklaşımlar gerekebilir. Ancak "V-Y" plasti sonrası ekstansör mekanizmada güçsüzlük, patella bajada artış ya da ekstansiyon kaybı gelişebilir. Tüberkül osteomisi geniş görüş açısı sağlamakta, kemik-kemik kaynama ile iyileşmesi de avantaj sağlamaktadır, ancak tibial tüberkülün superiora yer değiştirmesi (migrasyonu) ve tüberkül kırığı gibi dezavantajları mevcuttur. ${ }^{[2]}$

\section{Osteotomi Hattındaki Tespit Materyalleri}

Osteotomi tespit materyalleri (plak-vida, U-çivisi 'steypıl, staple', vb.); ağrı, irritasyon yapmıyor veya kemik içine gömülmüş ise çıkarılmayabilir, ancak tibial komponent yerleştirilmesine engel olacak ise çıkarılmalıdır (Şekil 4). Bu tespit materyalleri, tek aşamalı TDP cerrahisi esnasında veya iki aşamalı TDP öncesinde ayrı bir ameliyatla çıkarılabilir. Cerrahi iki aşamalı 

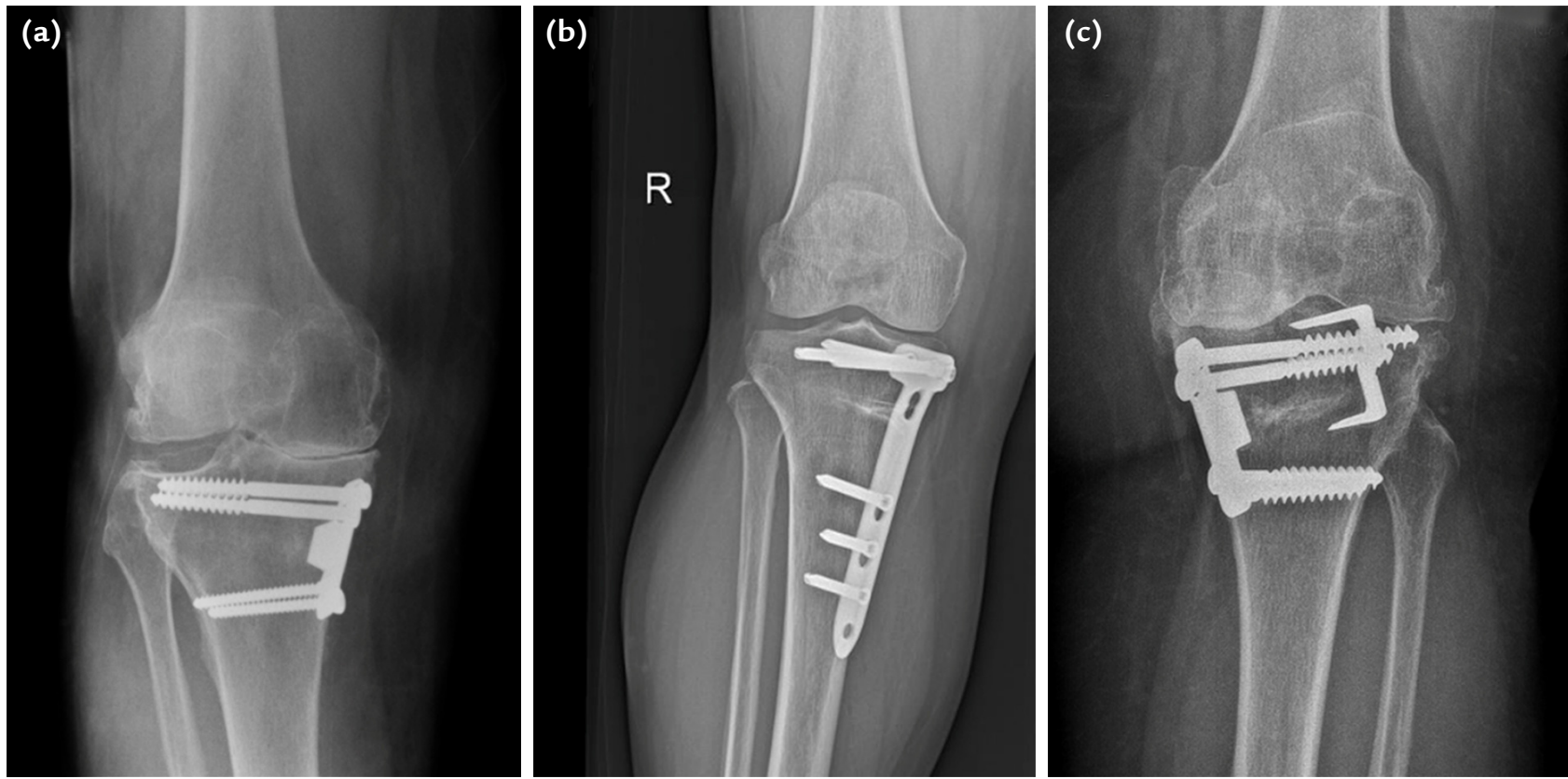

Şekil 4. a-c. PTVO tespiti için uygulanan farklı tespit materyallerinin radyolojik görüntüleri: metal bloklu plak-vida uygulaması (a), Tomofiks plağı-vida uygulaması (b) ve metal bloklu plak-vida ile basamaklı steypıl (staple) uygulaması (c).

yapılacaksa cerrahi işlemler arasında 4-6 hafta süre olmalıdır. Özellikle bloklu implantlar çıkarılırsa kemikte defekt ortaya çıkabilir. Ancak çoğu kemik defekt protez için risk oluşturmamaktadır. ${ }^{[2,3]}$

Ayrıca açık kama osteotomilerde kullanılan sentetik veya allogreftlerin cerrahi sorunlara neden olabileceği düşünülmelidir. PTVO hattına boşluk doldurmak için konan allogreftler veya kalsiyum trifosfat bloklar sert kemik dokuya dönüşebilirler. Özellikle tibial komponentin hazırlığı esnasında medullanın açılmasında zorluklara sebep olabilmektedir. Tibia medullasının açımasında dikkat edilmez ise tibial komponent uygun olmayan pozisyonda yerleştirilebilir. ${ }^{[2,3]}$

\section{Anatomik Kemik Deformiteleri}

Proksimal tibial osteotomiler sonrasında, tibia proksimalinde koronal, sagittal veya aksiyel planda deformiteler ortaya çıkabilir. Bu deformitelerin cerrahi öncesi değerlendirilmesi gerekir ve eklem çizgisine yakın olanlar TDP yapılırken düzeltilebilir. Koronal plan varus veya valgus deformitelerinde, tibia proksimal veya femur distal eklem yüzeyinden yapılacak kemik kesiler ile bu deformiteler düzeltilebilir. Hastanın TDP öncesi posterior tibial eğim açısı hesaplanarak, cerrahi sırasında açıyı düzeltmek için uygun kesiler planlanmalıdır. Aksiyel planda olan rotasyonel deformiteler hem tibiofemoral hem de patellofemoral eklem kinematiğini etkileyebilir. Rotasyonel deformiteler tibial komponentin doğru yerleştirilmesi ile düzeltilebilir. Ciddi deformitelerde TDP'ye ek olarak derotasyonal osteotomiler veya tibial tüberkül osteotomileri yapılması gerekebilir. ${ }^{[2,3]}$

Proksimal tibia valgus osteotomisi sonrasında tibia platosunun anatomik ekseni ile tibia medüller kanal anatomik ekseni arasında sapma meydana gelebilmektedir. ${ }^{[7]}$ MAKO tekniğinde bu değişim daha az olmakla birlikte laterale, LKKO ve dome ostetomisinde değişim daha fazla birlikte mediale doğru olmaktadır. TDP'ye geçiş sırasında uygun dizilim sağlamakta ve tibial komponentin doğru pozisyonda konumlandırılmasında zorluk yaşanabilmektedir. LKKO tekniği plato orta noktası ile tibial medulla orta noktasını en çok yaklaştıran teknik olması nedeniyle TDP'ye geçiş nispeten daha kolay olmaktadır. İntramedüller kılavuz veya stemli tibial komponent kullanıldığında, medulla içine yollanan kılavuz veya stem kemik medial korteksine temas edebilir. Stem ile tibial korteks arasında ortaya çıkan sıkışma klinikte ağrı olarak şikâyetlere neden olabilir. ${ }^{[8]}$ Bu durum, daha küçük tibial komponent ya da offsetli stem kullanılarak çözülebilir. ${ }^{[2]}$ Özellikle LKKO, tibiada metafizer kemik kaybına neden olduğu için, TDP'ye dönüşüm yapılırken tibia proksimalinden daha az kemik rezeke edilmeli ve fibula başına dikkat 
edilerek eklem çizgisi korunmalıdır. Meding ve ark., yaptıkları çalışmada LKKO sonrası TDP uyguladıkları hastalarda tibial kemik rezeksiyonu kalınlığını $3 \mathrm{~mm}$, primer TDP uyguladıkları hastalarında ise $7,5 \mathrm{~mm}$ olarak hesaplamışlardır. Bu nedenle tibial kemik rezeksiyonu yapılırken dikkatli olunmalıdır. ${ }^{[9]}$

\section{Bağ Dengesi}

Proksimal tibia valgus osteotomisi sonrası asimetrik yumuşak doku gerginlikleri olan hastalara TDP yapılırken koronal planda mekanik eksene dik yapılacak kemik kesiler, medial veya lateral gerginliğe bağlı olarak asimetrik kesi aralığına (fleksiyon-ekstansiyon boşluk dengesizliği) neden olabilir. PTVO sonrası ortaya çıkabilen varus tekrarı ile birlikte medial tibial plato aşınması olan hastalarda yeterli medial gevşetme önerilmektedir. MAKO sonrası aşırı valgus deformitesi olan olgularda iç yan bağ (medial kollateral ligament) yetmezliği, LKKO sonrası aşırı valgus gelişen olgularda ise lateral yumuşak dokularda gerginlik görülmektedir. Fleksiyon-ekstansiyon aralığını dengelemek için aşırı gevşetmeden kaçınılmalı ve valgus dizlerde kontrollü olarak sırasıyla arka çapraz bağ ve lateral yapılar gevşetilmelidir. ${ }^{[2]}$ MAKO sonrası TDP'ye geçişte medial gevşetmenin hastaların \%91,5'inde, lateral gevşetmenin ise \%46'sında; LKKO sonrası TDP'ye geçişte medial gevşetmenin $\% 55,5$, lateral gevşetmenin ise $\% 57,2$ oranında uygulandığını bildirilmiştir. ${ }^{[3]}$ Ameliyat sırasında mevcut deformiteye göre planlama yapılmalı ve fleksiyon-ekstansiyon aralığı dengelenmesi amaçlanmalıdır.

\section{Protez Seçenekleri}

Proksimal tibia valgus osteotomisi sonrası TDP dönüşümünde uygulanabilir protez seçenek ve özellikleri arasında; arka çapraz bağ (AÇB) kesen veya koruyan, çimentolu (sementli) veya çimentosuz (sementsiz), sabit veya hareketli insertli (ara parçalı) ve kısıtlayıcı protezler sayılabilir. PTVO sonrası hareket kısıtlılığı, AÇB kontraktürü veya yetmezliği gelişen olgularda fleksiyon-ekstansiyon boşluğunu ayarlamak kolay olduğu için, AÇB kesen protezlerin kullanılması tercih edilmektedir. AÇB kesen protezin klinik ve radyolojik sonuçlarının başarılı olduğunu bildiren çalışmalar mevcuttur. ${ }^{[9-12]}$ Akasaki ve ark., yaptıkları çalışmada $A C ̧ B$ kesen protezlerin eklem hareket açıklığının ve klinik skorlarının AÇB koruyanlara göre daha iyi olduğu belirtilmiştir. Özellikle ameliyat sonrası erken dönem $A C ̧ B$ yetmezliğine bağlı instabilite gelişme riskinin yüksek olması ve ameliyat sonrası eklem hareket açıklığının yetersiz olması AÇB koruyan protezlerin yapılmasını kısıtlamıştır. ${ }^{[10]}$ Hernigou ve ark., PTVO sonrası aşırı düzeltme yapılan hastalara TDP uygulanırken daha fazla yumuşak doku gevşetme gerektiğini ve $A C ̧ B$ kesen protez kullanılmasının sonuçları olumlu etkilediğini bildirmişlerdir. ${ }^{[12]}$ Son yıllarda AÇB koruyan protezlerin de diz stabilitesi ve klinik skorları ile revizyon oranlarının AÇB kesen protezler kadar başarılı olduğu bildirilmiştir (Şekil 5 ve 6).[11,13]

Proksimal tibia valgus osteotomisi sonrası TDP uygulamasında patellar yüzey değişimi, anterior diz ağrısına neden olması ve ikincil patella değişim riskinin oluşması nedeniyle önerilmemektedir. ${ }^{[14]}$ Fakat PTVO sonrası patella baja ve patellar tendon yapışıklıklarının ortaya çıkması dolayısıyla patella yüzey değiştirilmesini öneren çalışmalar da mevcuttur .[2,3,14] ïleri derece varus-valgus deformitesi olan olgular ile ameliyat sırasında kemik kesiler sonrası instabilite bulguları olan veya fleksiyon-ekstansiyon boşluk dengesi sağlanamayan olgularda yarı kısıtlayıcı veya menteşeli protezler kullanılabilir. ${ }^{[2-4,12]}$ Özellikle ciddi plato defekti olan olgularda kamalara, PTVO sonrası kaynamama olan olgularda greftlere, uzun stemlere veya kamalara ihtiyaç olabilir. ${ }^{[2]}$

Proksimal tibia valgus osteotomisi sonrası TDP uygulanırken, komponent tespitinde çimentolu (sementli) veya çimentosuz (sementsiz) seçenekler mevcuttur (Şekil 7). Batailler ve ark.'nın, PTVO sonrası sementsiz TDP uygulanan hastalar ile primer sementsiz TDP uygulanan hastaların orta dönem sonuçlarını karşılaştıran çalışmalarında, fonksiyonel ve radyolojik sonuçlar ile komplikasyon oranları arasında anlamlı fark görülmemiştir. Sekiz yıllık takiplerde sağkalım oranları arasında anlamlı fark bulunmamıştır (primer sementsiz TDP'de \%100, PTVO grubunda ise \%97,6). ${ }^{[15]}$ Hernigou ve ark., PTVO sonrası sabit insert ile hareketli insert kullanılarak TDP yapılan hastaları inceledikleri çalışmalarında iki grup arasında diz skorları, 10 yıllık sağkalım oranları (hareketli insert $\% 91,1$, sabit insert $\% 95,2$ ) ve radyolojik parametreler açısından anlamlı fark bulmamışlardır. ${ }^{[16]}$

\section{Klinik Sonuçlar}

Proksimal tibia valgus osteotomisi sonrası yapılan TDP'nin klinik ve radyolojik sonuçlarını inceleyen birçok çalışma mevcuttur. ${ }^{[10-13]}$ Chalmers ve ark., kapalı ve açık kama PTVO sonrası AÇB kesen çimentolu TDP yapılan 207 hastanın 231 dizini değerlendirmişler. Hastaların 10 yıllık sağkalım oranının \%97 olduğunu bildirmişlerdir. Ancak hastaların \%4'üne anestezi altında manipülasyon gerektiğini, \%3'üne ise instabilite nedeniyle revizyon yapıldığını bildirmişlerdir. ${ }^{[8]}$ On dokuz çalışmayı içeren güncel meta-analiz çalışmasında PTVO sonrası TDP uygulamanın protez sağkalımı üzerine olumsuz etkisi olmadığını bildirmişlerdir. ${ }^{[17]}$

Proksimal tibia valgus osteotomisi sonrası TDP ile primer TDP sonuçlarını karşılaştıran çalışmaların 

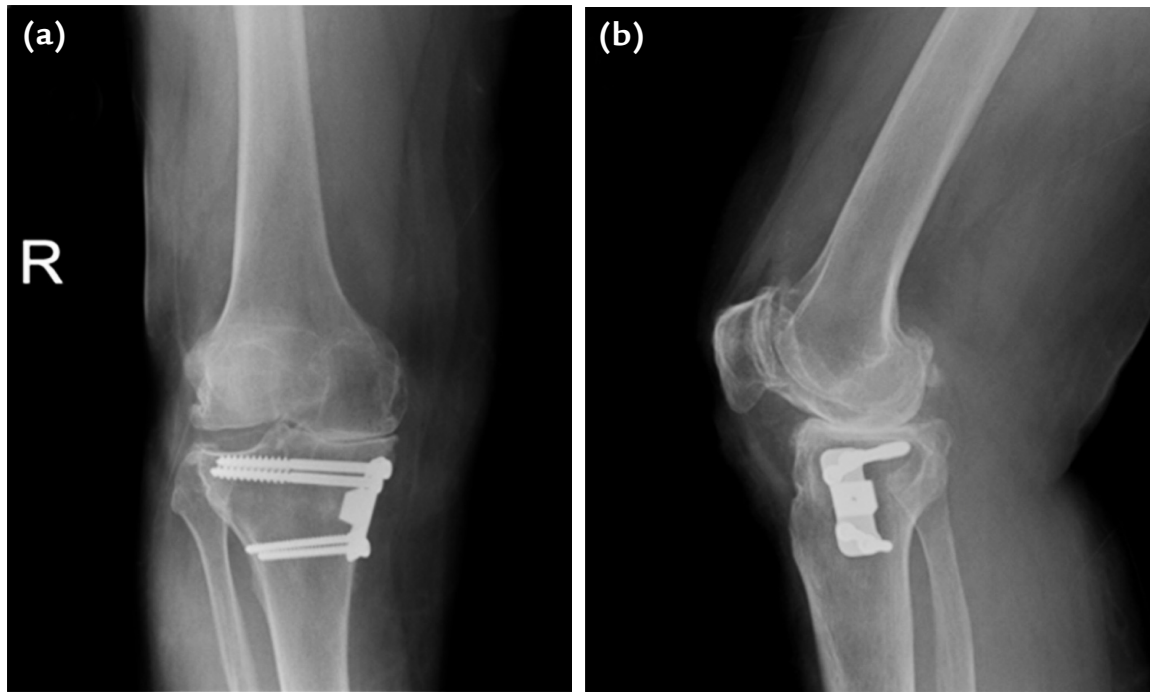

Şekil 5. a-d. Yetmiş beş yaşında erkek hasta, 15 yıl önce sağ diz medial açık kama valgus osteotomisi yapılmış: arka çapraz bağ koruyan TDP öncesi (a, b) ve sonrası (c, d) ön-arka ve yan (lateral) diz grafileri.
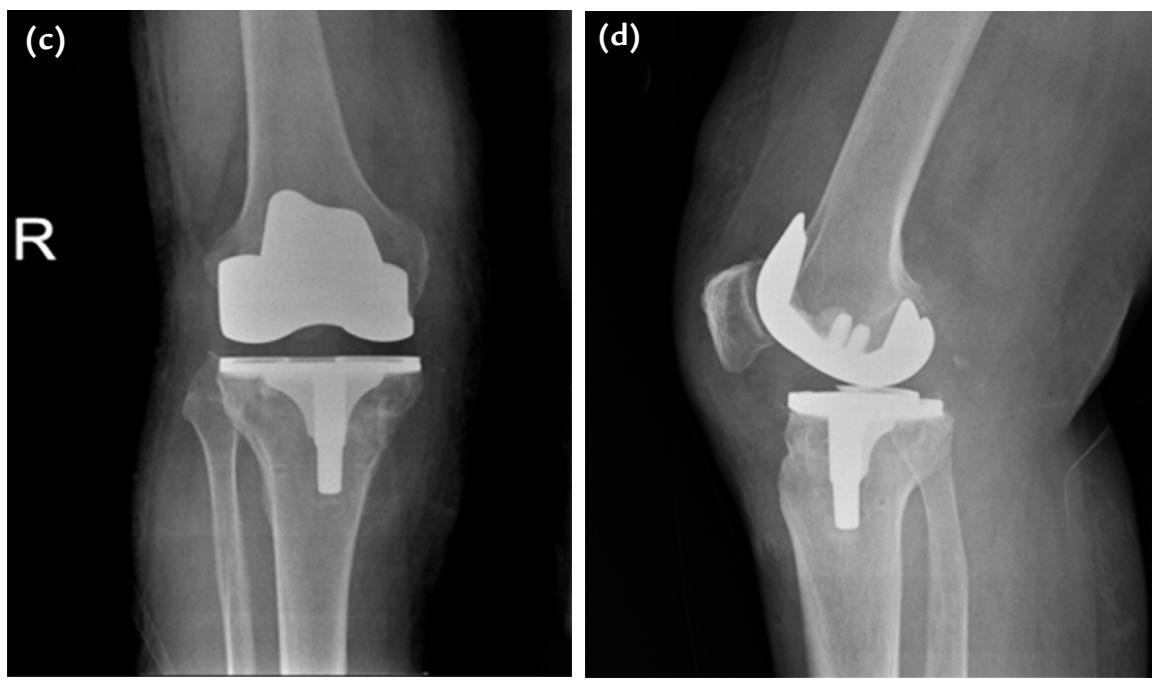

sonuçları farklııı arz etmektedir. ${ }^{[8,18-20]} 1995-2005$ yılları arası Finlandiya artroplasti kayıtlarına göre PTVO sonrası TDP yapılan 1.036 hasta ile primer TDP yapılan 4.143 hastanın 5, 10, 15 yıllık takiplerini inceleyen çalışmada; primer TDP yapılan hastalarda sağkalım oranları daha yüksek bulunmuştur. Sağkalım oranları; osteotomi sonrası TDP için, 5 yıl \%95,3, 10 yıl \%91,8 ve 15 yıl \%88,4; primer TDP için, 5 yıl \%97,2, 10 yıl \%94,5 ve 15 yıl \%90,6 olarak değerlendirilmiştir. Ayrıca osteotomi sonrası TDP hastalarındaki revizyon oranları, primer TDP grubuna göre anlamlı yüksek bulunmuştur (osteotomi sonrası TDP için \%9, primer TDP için \%6,2). ${ }^{[18]} 1994-2013$ yılları arasındaki Norveç artroplasti kayıtlarına göre primer TDP yapılan 31.077 hasta ile PTVO sonrası TDP yapılan 1.399 hasta karşılaştırılmış. On yıllık sağkalım ve revizyon oranları arasında anlamlı fark bulunmamıştır. Sağkalım oranları; osteotomi sonrası TDP için \%93,8, primer TDP için \%92,6 olarak değerlendirilmiştir. Ancak ameliyat öncesi, esnası ve sonrasında komplikasyon oranı ve ameliyat süresinin osteotomi sonrası TDP grubunda daha yüksek olduğu bildirilmiştir. ${ }^{[19]}$

2009 yılında yayımlanan bir meta-analizde PTVO sonrası yapılan TDP'lerin primer TDP'ye göre; ameliyat süresinin daha uzun olduğunu, daha fazla lateral gevşetme yapıldığını, daha sık tibial tüberkül osteotomisine ihtiyaç duyulduğunu ve $10^{\circ}$ kadar daha az hareket açıklığı olduğunu bildirmiştir. Ancak, kullanılan insert kalınlığı, klinik sonuçlar açısından, gevşeme ve revizyon oranları arasında fark bulunmadığını belirtmişlerdir. ${ }^{[20]}$ Güncel meta-analiz çalışmasında revizyon oranları incelendiğinde PTVO sonrası yapılan 

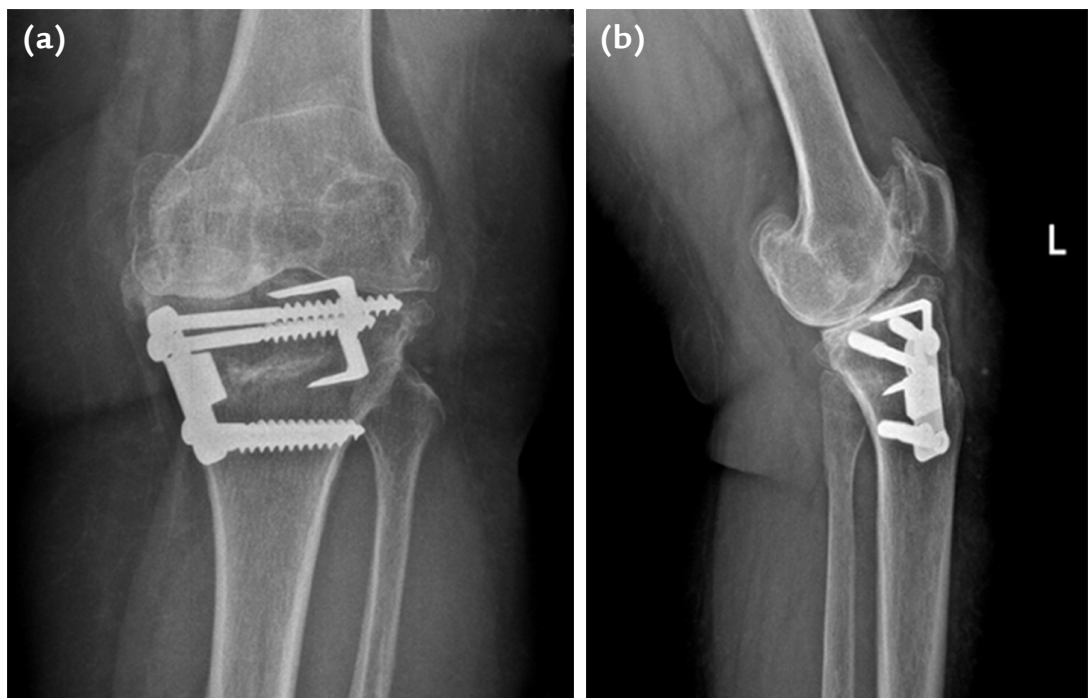

Şekil 6. a-d. Altmış sekiz yaşında kadın hasta, 15 yıl önce sol diz medial açık kama valgus osteotomisi yapılmış: arka çapraz bağ kesen TDP öncesi (a, b) ve sonrası (c, d) önarka ve yan (lateral) diz grafileri.
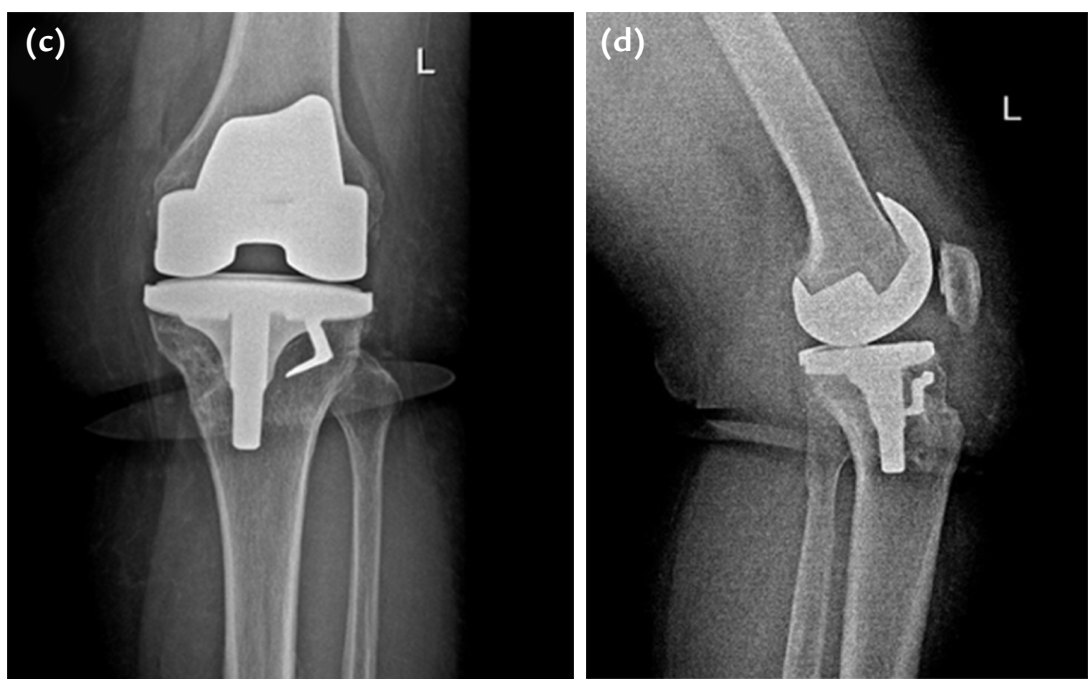

TDP'de revizyon oranlarının anlamlı daha yüksek (osteotomi sonrası TDP, \%7,66; primer TDP, \%3,79) bulunmuş̧tur. Ayrıca cerrahi sürenin ve enfeksiyon riskinin osteotomi sonrası yapılan TDP'de daha yüksek olduğu görülmüş̧tür. ${ }^{[8]}$

Medial açık kama osteotomisi ile LKKO sonrası TDP yapılan hastaları karşılaştıran çalışmaların sonuçlarında farklılıklar bulunmaktadır. ${ }^{[21-26]}$ Birçok çalışmada MAKO ile LKKO sonrasında yapılan TDP olgularının klinik ve radyolojik sonuçları arasında anlamlı fark olmadığı bildirilmiştir. ${ }^{[21,22]}$ Han ve ark.'nın 2015 yılında yayımladıkları sekiz çalışmayı derledikleri meta-analiz çalışmasında; medial açık kama ile lateral kapalı kama osteotomi sonrası TDP yapılan hastaların radyolojik ve klinik sonuçları benzer olmakla birlikte, cerrahlar tarafindan LKKO olan grupta daha fazla kuadriseps snip ve tibial tüberkül osteotomisi gerektiği vurgulanmıştır. ${ }^{[23]}$ Kuvashima ve ark., üç boyutlu bilgisayarlı tomografi (BT) üzerinden MAKO ile LKKO sonrası TDP uygulama cerrahi simülasyon ile yaptıkları çalışmada, tibial komponent distali ile endosteal korteks arasındaki mesafenin kapalı kama osteotomisinde daha az olduğunu belirtmişlerdir. ${ }^{[24]}$ Ehlinger ve ark., çok merkezli MAKO ve LKKO sonrası TDP yapılan hastaları karşılaştırdıkları çalışmalarında, her iki grup arasında klinik skorları ve diz stabilite skorları arasında fark bulunmamıştır. ${ }^{[25]}$ Ancak, MAKO grubunda daha sık eski insizyonlar kullanılmış, LKKO grubunda ise daha sık geç komplikasyon görülmüştür. PTVO sonrası TDP'ye geçişte sık görülen komplikasyon oranları \%12-35 olarak verilirken, en sık görülenler eklem hareket kısıtlılığı, 

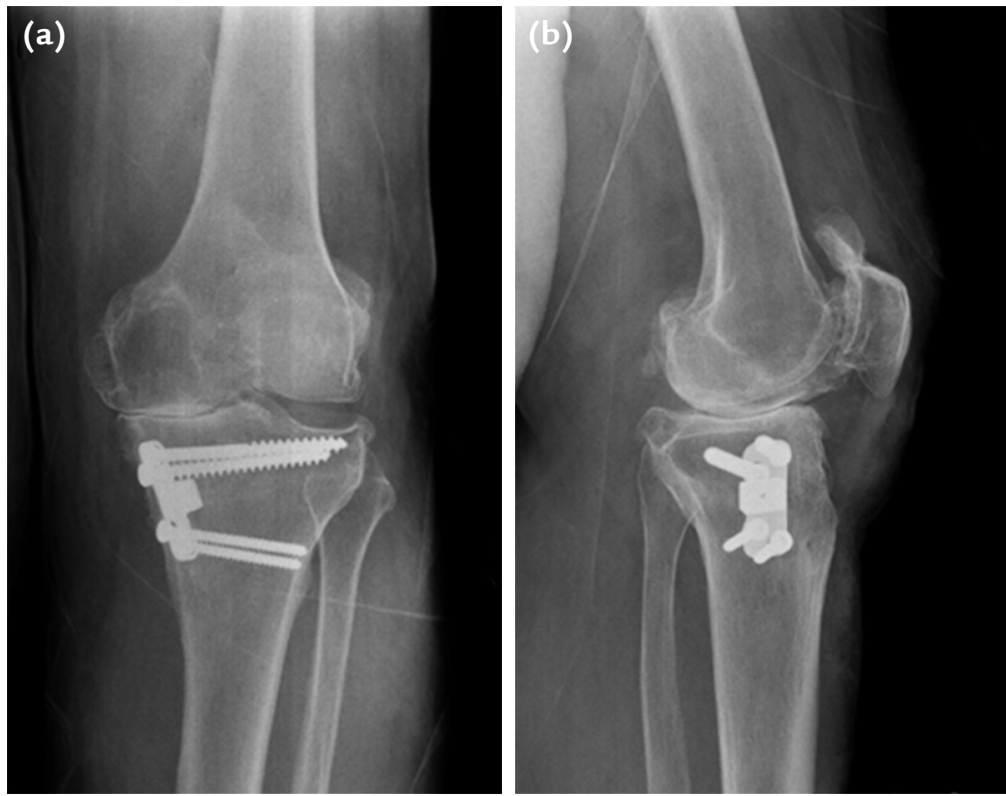

Şekil 7. a-d. Yetmiş dört yaşında kadın hasta, 19 yıl önce sol diz medial açık kama valgus osteotomisi yapılmış: arka çapraz bağ kesen çimentolu TDP öncesi $(a, b)$ ve sonrası $(c, d)$ ön-arka ve yan (lateral) diz grafisi, TDP uygulanırken PTO plağı yerinde bırakılmış (c, d).
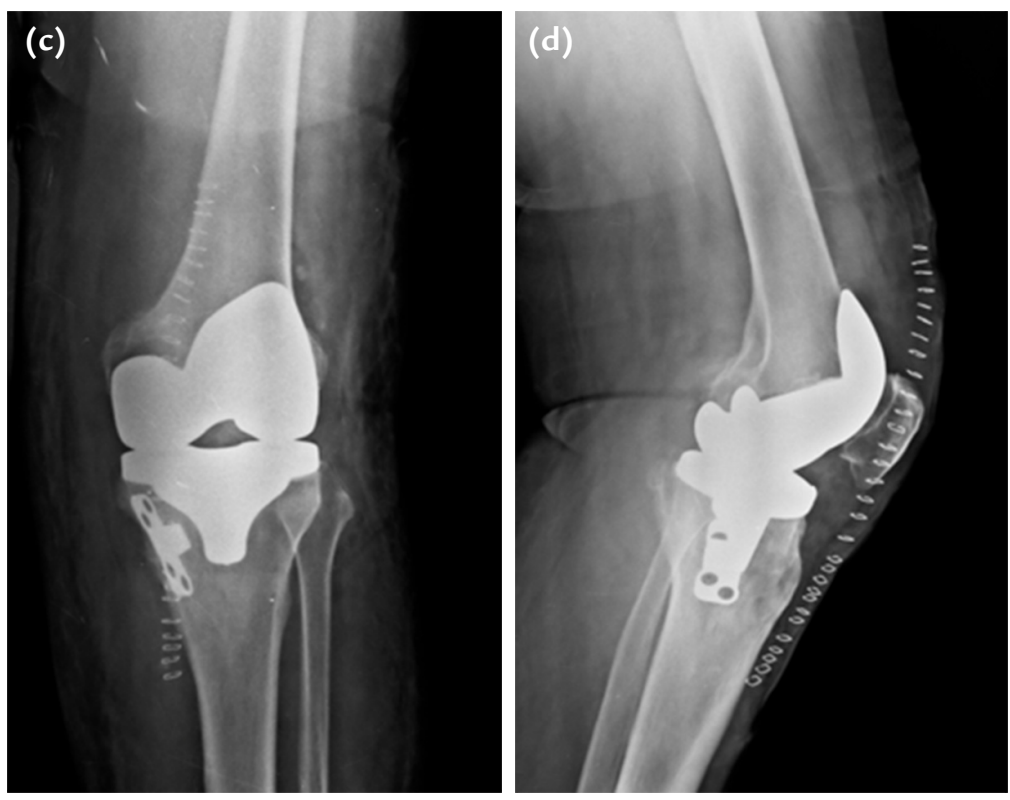

komponentlerde erken gevşeme, patella subluksasyonu ve instabilite olarak belirtilmektedir. ${ }^{[26]}$

\section{DISTAL FEMORAL OSTEOTOMI SONRASI TDP}

Valgus dizilim bozukluğu ve lateral kompartman artrozu olan hastalarda; distal femoral varus osteotomisi, osteoartritin ilerlemesini yavaşlatmakta ve klinik şikâyetleri azaltmakta etkindir. ${ }^{[27-32]}$

Distal femoral varus osteotomisi (DFVrO), medial kapalı kama ya da lateral açık kama şeklinde yapılabilmektedir; $10^{\circ}$ 'den daha az düzeltme gerektiğinde lateral açık kama, $10^{\circ}$ 'den daha fazla düzeltme gerekliliğinde ise medial kapalı kama osteotomisi uygulanabilir. Medial açık kama osteotomisinde 15 yıllık takiplerde \%58, 20 yıllık takiplerde ise \%21,5, lateral kapalı kama osteotomisinde de sekiz yıllık takiplerde \%84-100 başarılı sonuçlar bildirilmiştir ve DFVrO sonrası TDP geçiş zaman aralığı en sık 10 ile 15 yıllar arasındadır. ${ }^{[27]}$

Distal femoral varus osteotomisi sonrası TDP cerrahisi primer TDP cerrahisine göre birçok farklılık ve zorluk 
içermektedir. Lateral kompartman ve/veya medial kompartman artrozunda ilerleme, eklem hareket kısıtlılı̆ı ve patellofemoral artroz DFVrO sonrası sık görülen uzun dönem sorunlardır. ${ }^{[33]}$ Ayrıca cilt insizyon yerleşimi, eklem hareket kısıtlılığı, yeterli görüş sağlayacak eklem açılması, osteotomi implantının varlığı, kemik deformitesi, kemik stok-kalite yetersizliği ve bağ dengesi sorunları da TDP'ye geçişi zorlaştıran faktörlerdir. ${ }^{[27]}$

Önceki insizyona ait nedbe dokuları dikkate alınarak TDP insizyonu planlanmalı ve uygun olgularda standart orta hat insizyon tercih edilmelidir. Eklem hareket kısıtıılığı eklemde yeterli görüş alanını sağlamayı zorlaştırabilir ve patellar tendon yaralanma riskini artırabilir. Bu sorunun önüne geçmek için kuadriseps snip yaklaşım veya tibial tüberkül osteotomisi için hazırlık yapılmalıdır. DFVrO'ya ait tüm implantların çıkarılması konusunda görüş birliği yoktur. ${ }^{[29]}$ Güncel bir meta-analiz incelenmesinde olguların \%59,7'sinde TDP yapılırken, \%20,8'inde ise TDP öncesi ayrı bir cerrahi seansta implantlar çıkarılmaktadır. \%19,4 olguda ise, DFVrO implantları çıkarılmamaktadır. Bazı yazarlar da sadece implantların bir kısmını çıkarmaktadırlar. ${ }^{[27,31]}$ DFVrO sonrası rotasyonel deformitelerin olabileceği unutulmamalı ve şüpheli durumlarda BT ile değerlendirilmelidir. Femur hazırlanırken intramedüller kılavuzun giriş yeri standart giriş yerinin lateralinden olmalıdır. Aksi takdirde femoral komponent varus pozisyonunda kalabilir. Bu durumu önlemek amacıyla ekstramedüller kılavuz kullanılabilir. ${ }^{[32]}$ TDP sırasında bağ dengesini sağlamak için çoğu yazar arka çapraz bağ kesen protez kullanmışlardır. ${ }^{[28-32]}$ Cerrahi sırasında bağ dengesinin sağlanamadığı durumlarda kısıtlayıcı protezlerin ve oluşabilecek defektler içinde allogreftler veya blokların ameliyathanede bulunması önerilmektedir. ${ }^{[27]}$

\section{Klinik Sonuçlar}

Distal femoral varus osteotomisi sonrası TDP'ye dönüş yapılan hastalarda klinik ve radyolojik sonuçların başarılı olduğunu bildiren çalışmalar mevcuttur. ${ }^{[27-32]}$ Cameron ve ark., sekiz olguluk serilerinde önceden uygulanan DFVrO'nun TDP'lerin klinik ve radyolojik sonuçlarını etkilemediğini bildirmişlerdir. ${ }^{[30]}$ Nelson ve ark., 2003 yılında yaptıkları çalışmalarında DVFrO sonrası yapılan TDP'nin hasta şikâyetlerini azaltmakta ve fonksiyonel skorları iyileştirmede etkin olduğunu belirtmişlerdir. Ancak femoral intramedüller kılavuz kullanıldığında femoral komponentin varus pozisyonunda kalabileceği için ekstramedüller kılavuz kullanılmasını tavsiye etmişlerdir. Ayrıca primer TDP'ye göre osteotomi hastalarının klinik sonuçlarının daha başarısız olduğunu bulmuşlardır. ${ }^{[32]}$ Gaillard ve ark., DVFrO sonrası TDP yapılan hastalar ile primer TDP yapılan hastaları karşılaştıran çalışmalarında orta dönem klinik sonuçların benzer olduğunu ancak cerrahi sırasında ortaya çıkan lateral bağ dengesizliğinin, patellar tendon yaralanma riskinin ve tibia lateral eklem yüzünde kemik defektinin daha fazla olduğunu bildirmişlerdir. ${ }^{[29]}$ Chalmers ve ark., DFVrO sonrası arka çapraz bağ kesen TDP uyguladıkları hastaların 10 yılık takiplerinde $\% 88$ sağkalım olduğunu göstermişlerdir. Elli yaş altı hastalarda revizyon oranının daha yüksek olduğunu, hastaların \%13'ünde varus-valgus kısıtlayıcı protez uygulandığını belirtmişlerdir. Ameliyat sonrası instabilite ve hareket kısıtlılığının primer TDP'ye göre daha fazla olduğu söylenmiştir. ${ }^{[31]}$ Kosashvili ve ark., DFVrO sonrası arka çapraz bağ kesen TDP kullandıkları hastaların ameliyat sırasında bağ dengelenmesi sağladıktan sonra stem veya kısıtlayıcı protez gereksiniminin olmadığını bildirmişlerdir. ${ }^{[28]}$

\section{SONUÇ}

Diz çevresi osteotomileri sonrası TDP uygulanacak olgularda ameliyat öncesi planlamanın iyi yapılması tedavi başarısını doğrudan etkilemektedir. Daha önce yapılan insizyon nedbelerinin yerleşimleri dikkate alınarak uygun insizyon seçimi yapılması gereklidir. Ayrıca lateral diz grafilerinde patella yüksekliğinin değerlendirilmesi, ameliyat esnasında patellanın laterale devrilmesi veya dışa döndürülmesinde (everte edilmesinde) yaşanabilecek sorunlara karşı hazırlıklı olmayı sağlayacaktır. Tibia ve femuru içine alan diz ön-arka ve yan grafilerle hem tibia hem de femurda kullanılacak kılavuz, tekniğe göre değerlendirilmeli ve ameliyathanede revizyon protez ile stem seçenekleri hazır bulundurulmalıdır. Ayrıca, oluşabilecek bağ dengesizliği açısından hastaların ameliyat öncesi klinik değerlendirilmesi yapılmalıdır. Doğru hazırlık ve iyi planlama sonrasında uygulanacak olan TDP cerrahisi ile başarılı klinik ve radyolojik sonuçlar elde edilebilir.

\section{KAYNAKLAR}

1. Windsor RE, Insall JN, Vince KG. Technical considerations of total knee arthroplasty after proximal tibial osteotomy. J Bone Joint Surg Am 1988;70(4):547-55. Crossref

2. Song SJ, Bae DK, Kim KI, Lee CH. Conversion Total Knee Arthroplasty after Failed High Tibial Osteotomy. Knee Surg Relat Res 2016;28(2):89-98. Crossref

3. Chen X, Yang Z, Li H, Zhu S, Wang Y, Qian W. Higher risk of revision in total knee arthroplasty after high tibial osteotomy: a systematic review and updated meta-analysis. BMC Musculoskelet Disord 2020;21(1):153. Crossref

4. Bae DK, Song SJ, Yoon KH. Total knee arthroplasty following closed wedge high tibial osteotomy. Int Orthop 2010;34(2):283-7. Crossref

5. Franco V, Cerullo G, Cipolla M, Gianni E, Puddu G. Open wedge high tibial osteotomy. Tech Knee Surg 2002;1:43-53. Crossref

6. Chae DJ, Shetty GM, Lee DB, Choi HW, Han SB, Nha KW. Tibial slope and patellar height after opening wedge high tibia osteotomy using autologous tricortical iliac bone graft. Knee 2008;15(2):128-33. Crossref 
7. Papp M, Csernátony Z, Kazai S, Károlyi Z, Róde L. The patella and tibial condyle position after combined and after closing wedge high tibial osteotomy. Knee Surg Sports Traumatol Arthrosc 2007;15(6):769-80. Crossref

8. Chalmers BP, Limberg AK, Tibbo ME, Perry KI, Pagnano MW, Abdel MP. Total knee arthroplasty after high tibial osteotomy results in excellent long-term survivorship and clinical outcomes. J Bone Joint Surg Am 2019;101(11):9708. Crossref

9. Meding JB, Keating EM, Ritter MA, Faris PM. Total knee arthroplasty after high tibial osteotomy. A comparison study in patients who had bilateral total knee replacement. J Bone Joint Surg Am 2000;82(9):1252-9. Crossref

10. Akasaki Y, Matsuda S, Miura H, Okazaki K, Moro-oka TA, Mizu-uchi H, Iwamoto Y. Total knee arthroplasty following failed high tibial osteotomy: mid-term comparison of posterior cruciate-retaining versus posterior stabilized prosthesis. Knee Surg Sports Traumatol Arthrosc 2009;17(7):795-9. Crossref

11. Chen JY, Lo NN, Chong HC, Pang HN, Tay DK, Chin PL, Chia SL, Yeo SJ. Cruciate retaining versus posterior stabilized total knee arthroplasty after previous high tibial osteotomy. Knee Surg Sports Traumatol Arthrosc 2015;23(12):3607-13. Crossref

12. Hernigou $P$, Duffiet $P$, Julian D, Guissou I, Poignard A, Flouzat-Lachaniette $\mathrm{CH}$. Outcome of total knee arthroplasty after high tibial osteotomy: does malalignment jeopardize the results when using a posterior-stabilized arthroplasty? HSS J 2013;9(2):134-7. Crossref

13. El-Galaly A, Nielsen PT, Jensen SL, Kappel A. Prior High Tibial Osteotomy Does Not Affect the Survival of Total Knee Arthroplasties: Results From the Danish Knee Arthroplasty Registry. J Arthroplasty 2018;33(7):2131-5.e1. Crossref

14. Amendola A, Bonasia DE. Results of high tibial osteotomy: review of the literature. Int Orthop 2010;34(2):155-60. Crossref

15. Batailler C, Fary C, Denjean S, Gaillard T, Lustig S. High Midterm Survival Rate of Uncemented Total Knee Arthroplasty After High Tibial Osteotomy: A Case-Control Study. J Arthroplasty 2020;35(6):1595-9. Crossref

16. Hernigou P, Huys M, Pariat J, Roubineau F, Flouzat Lachaniette $\mathrm{CH}$, Dubory A. Comparison of fixed-bearing and mobile-bearing total knee arthroplasty after high tibial osteotomy. Int Orthop 2018;42(2):317-22. Crossref

17. Rodriguez-Merchan EC. Does a Previous High Tibial Osteotomy (HTO) Influence the Long-term Function or Survival of a Total Knee Arthroplasty (TKA)? Arch Bone Jt Surg 2018;6(1):19-22. https://www.ncbi.nlm.nih.gov/pmc/ articles/PMC5799594/

18. Niinimäki $T$, Eskelinen A, Ohtonen P, Puhto AP, Mann BS, Leppilahti J. Total knee arthroplasty after high tibial osteotomy: a registry-based case-control study of 1,036 knees. Arch Orthop Trauma Surg 2014;134(1):73-7. Crossref

19. Badawy M, Fenstad AM, Indrekvam K, Havelin LI, Furnes $O$. The risk of revision in total knee arthroplasty is not affected by previous high tibial osteotomy. Acta Orthop 2015;86(6):734-9. Crossref

20. van Raaij TM, Reijman M, Furlan AD, Verhaar JA. Total knee arthroplasty after high tibial osteotomy. A systematic review. BMC Musculoskelet Disord 2009;10(1):88. Crossref
21. Preston S, Howard J, Naudie D, Somerville L, McAuley J. Total knee arthroplasty after high tibial osteotomy: no differences between medial and lateral osteotomy approaches. Clin Orthop Relat Res 2014;472(1):105-10. Crossref

22. Bastos Filho R, Magnussen RA, Duthon V, Demey G, Servien E, Granjeiro JM, Neyret P. Total knee arthroplasty after high tibial osteotomy: a comparison of opening and closing wedge osteotomy. Int Orthop 2013;37(3):427-31. Crossref

23. Han JH, Yang JH, Bhandare NN, Suh DW, Lee JS, Chang YS, Yeom JW, Nha KW. Total knee arthroplasty after failed high tibial osteotomy: a systematic review of open versus closed wedge osteotomy. Knee Surg Sports Traumatol Arthrosc 2016;24(8):2567-77. Crossref

24. Kuwashima $U$, Tashiro $Y$, Okazaki K, Mizu-uchi $H$, Hamai $\mathrm{S}$, Murakami K, Iwamoto Y. Comparison of the impact of closing wedge versus opening wedge high tibial osteotomy on proximal tibial deformity and subsequent revision to total knee arthroplasty. Knee Surg Sports Traumatol Arthrosc 2017;25(3):869-75. Crossref

25. Ehlinger M, D'Ambrosio A, Vie P, Leclerc S, Bonnomet F, Bonnevialle P, Lustig S, Parratte S, Colmar M, Argenson JN. Total knee arthroplasty after opening- versus closing-wedge high tibial osteotomy. A 135-case series with minimum 5-year follow-up. Orthop Traumatol Surg Res 2017;103(7):1035-9. Crossref

26. Farfalli LA, Farfalli GL, Aponte-Tinao LA. Complications in total knee arthroplasty after high tibial osteotomy. Orthopedics 2012;35(4):e464-8. Crossref

27. Luceri F, Tamini J, Ferrua P, Ricci D, Batailler C, Lustig S, Servien E, Randelli PS, Peretti GM. Total knee arthroplasty after distal femoral osteotomy: a systematic review and current concepts. SICOTJ 2020;6:35. Crossref

28. Kosashvili $Y$, Gross AE, Zywiel MG, Safir O, Lakstein D, Backstein D. Total knee arthroplasty after failed distal femoral varus osteotomy using selectively stemmed posterior stabilized components. J Arthroplasty 2011;26(5):738-43. Crossref

29. Gaillard R, Lording T, Lustig S, Servien E, Neyret P. Total knee arthroplasty after varus distal femoral osteotomy vs native knee: similar results in a case control study. Knee Surgery Sport Traumatol Arthrosc 2017;25(11):3522-9. Crossref

30. Cameron HU, Park YS. Total knee replacement after supracondylar femoral osteotomy. Am J Knee Surg 1997;10(2):70-1; discussion 71-2. https://pubmed.ncbi. nlm.nih.gov/9131236/

31. Chalmers BP, Limberg AK, Athey AG, Perry KI, Pagnano MW, Abdel MP. Total knee arthroplasty after distal femoral osteotomy. Bone Jt J 2019;101-B(6):660-6. Crossref

32. Nelson CL, Saleh KJ, Kassim RA, Windsor R, Haas S, Laskin $\mathrm{R}$, Sculco $\mathrm{C}$. Total knee arthroplasty after varus osteotomy of the distal part of the femur. J Bone Jt Surg 2003;85(6):10625. Crossref

33. Wang J-W, Hsu C-C. Distal femoral varus osteotomy for osteoarthritis of the knee. J Bone Joint Surg Am 2006;88(Suppl 1 Pt 1):100-8. Crossref 